\title{
Posterior migration of lumbar disc herniation - imaging dilemma due to contrast contraindication: a case report*
}

\author{
Hérnia discal lombar com migração posterior - dilema em diagnóstico por imagem devido a contraindicação \\ ao uso de contraste: relato de um caso \\ Fabrício Guimarães Gonçalves ${ }^{1}$, Prasad Baladev Hanagandi ${ }^{2}$, Carlos Ignacio Torres ${ }^{3}$, Raquel
DelCarpio-O'Donovan $^{4}$
}

Abstract Disc herniation with posterior epidural migration is a rare and often symptomatic entity. Multiple are the natural barriers that prevent this pattern of migration. Enhanced magnetic resonance imaging is the diagnostic modality of choice in these cases. The diagnostic dilemma in this case was the contraindication to the use of contrast since the patient was known to have chronic renal failure.

Keywords: Lumbar hernia; Complication; Epidural space; Posterior; Magnetic resonance imaging; Contrast.

Resumo Hérnia discal com migração epidural posterior é uma entidade rara e frequentemente sintomática. Múltiplas são as barreiras naturais que impedem esse padrão de migração. A ressonância magnética contrastada é a modalidade diagnóstica de escolha nesses casos. O dilema diagnóstico, neste caso, foi a contraindicação ao uso de contraste, uma vez que o paciente era portador de insuficiência renal crônica.

Unitermos: Hérnia lombar; Complicações; Espaço epidural; Posterior; Ressonância magnética; Contraste.

Gonçalves FG, Hanagandi PB, Torres Cl, DelCarpio-O'Donovan R. Posterior migration of lumbar disc herniation - imaging dilemma due to contrast contraindication: a case report. Radiol Bras. 2012 Mai/Jun;45(3):170-172.

\section{INTRODUCTION}

Disc herniation $(\mathrm{DH})$ with posterior epidural migration (PEM) is a quite rare and symptomatic entity ${ }^{(\mathbf{1})}$. Its imaging diagnosis is usually difficult, as it can mimic a variety of conditions involving the epidural space ${ }^{(2)}$. In this report we present a case of a herniated disc with PEM and emphasize the imaging dilemma due to contraindication for contrast administration.

\section{CASE REPORT}

A 51-year-old man was admitted to the emergency room with a two-year history of intermittent low back pain that has progressed significantly in the last three days.

* Study developed at Montreal General Hospital, Department of Diagnostic Neuroradiology, McGill University Health Center (MUHC), Montreal, Quebec, Canada, and at the Neuroradiolog Department of Infinita Diagnóstico por Imagem, Brasília DF, Brazil.

1. MD, Neuroradiologist Chief of the Department of Neuroradiology of Infinita Diagnóstico por Imagem, Brasília, DF, Brasil, Clinical Fellow, Montreal General Hospital, McGill University Health Center (MUHC), Montreal, Quebec, Canada.

2. MD, Neuroradiology Clinical Fellow, Montreal General Hospital, McGill University Health Center (MUHC), Montreal, Quebec, Canada.

3. MD, Neuroradiologist, Montreal General Hospital, McGill University Health Center (MUHC), Montreal, Quebec, Canada.

4. MD, Neuroradiologist, Professor and Vice Chair of Radiology, Associate Director of Radiology at McGill University Health Center (MUHC) and Program Director of Neuroradiology, Montreal, Quebec, Canada.
The patient was not known for a malignancy and did not have a history of trauma. Physical examination was remarkable for low back pain radiating to the anterior and lateral aspect of the left thigh, which worsened with hip flexion. No signs of urinary retention or bowel dysfunction were found. There were no constitutional symptoms. The axillary temperature and the erythrocyte sedimentation rate were normal. The laboratory analysis was negative for an infectious process. He had a long history of diabetes mellitus, hypertension and renal insufficiency.

At the emergency room, plain films of the lumbar spine were obtained, which failed to reveal any signs of acute fractures. Magnetic resonance imaging (MRI) examination was obtained for further evaluation of the lumbar spine and demonstrated a T1 hypointense and T2WI hyperintense epidural mass at L2-3 on the left side (Figure 1), with no cleavage plane with the intervertebral disc. This mass was extending to the posterior epidural space, occupying most

Corresponding author: Fabrício Guimarães Gonçalves, MD. 1650 Cedar Avenue, Room C5 118 Montreal, QC H3G 1A4 Canada. E-mail: goncalves.neuroradio@gmail.com

Received August 8, 2011. Accepted after revision January 10, 2012. of the height of the L2 vertebral body (Figure 2). The thecal sac was partially encased, compressed and deviated to the right side. Contrast was contraindicated due to known history of renal insufficiency. Epidural hematoma, epidural empyema, nerve sheath tumor and meningioma were included in the differential diagnosis. Though rare, PEM of disc was also considered in the list of differential diagnosis. The absence of trauma or an infection syndrome made the possibility of an epidural empyema or hematoma less likely.

The patient underwent surgery and the epidural soft tissue was excised by a L3 hemilaminectomy and excisional biopsy was performed (Figure 3). The epidural material was adherent to the dura but however completely excised. The pathological report was consistent with a disc fragment in the posterior epidural space. The pain and sensory symptoms markedly improved during the first few weeks after the surgery.

\section{DISCUSSION}

$\mathrm{DH}$ is a displacement of disc material beyond the limits of the intervertebral disc space. According to the shape, DH can be classified as protrusions or extrusions. Disc 


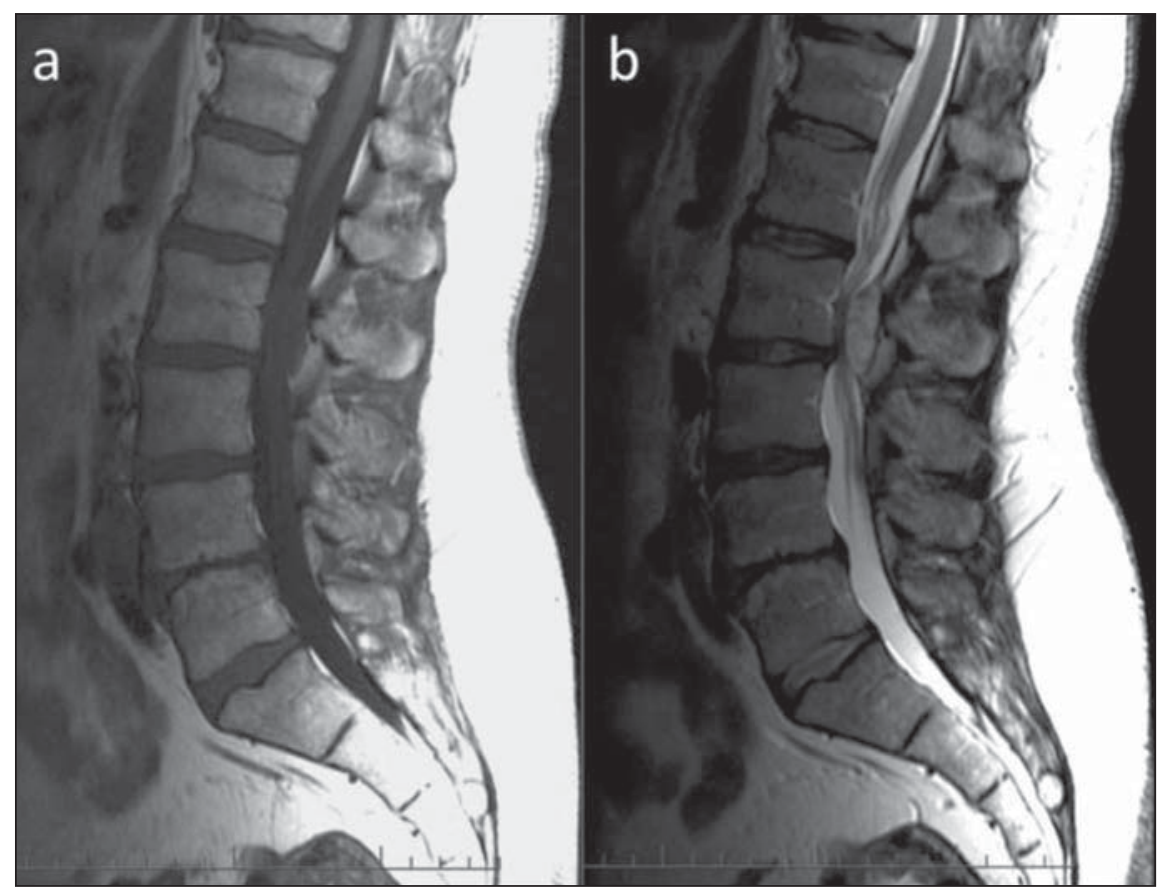

Figure 1(a,b). Sagittal T1 and T2WI demonstrates a posteriorly migrated herniated disc fragment compressing the cauda equina roots at L2-3 level.

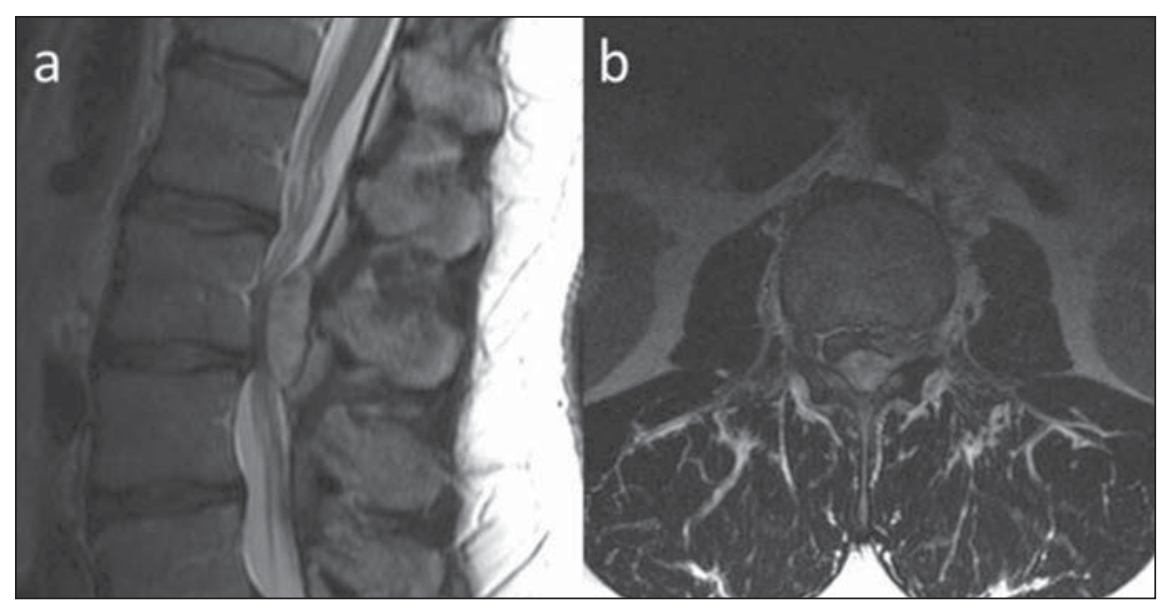

Figure 2(a,b). Sagittal T2 (in detail) and axial T2WI at the same level showing the epidural disc fragment compressing the roots and encasing the thecal sac on the left side.

sequestration is a type of disc extrusion in which the disc has lost its continuity with the native disc. DH may also be categorized in contained or uncontained, whether these are covered or not by the annulus fibrosus ${ }^{(3)}$. In relation to the dural sac, DH is commonly located anteriorly or antero-laterally $^{(2)}$. DH with PEM is a quite rare entity with 31 cases reported in the literature $^{(4)}$. The first case of a DH with PEM was reported by Lichtor in $1989^{(5)}$. DH with PEM is usually a sequestered disc without annulus fibrosus covering. In a series of
2880 patients operated for lumbar DH, Sengoz et al. reported an incidence of $0.27 \%$. In their series the migrated fragments were located mainly at the L3-4 level (75\%) and the L4-5 (25\%) ${ }^{(4)}$.

Anatomical peculiarities of the lumbar region may explain the rarity of this condition. The first major barrier for posterior migration is the posterior longitudinal ligament, a very strong ligament, which almost never ruptures as opposed to the annulus fibrosus. Another obstacle is a midline septum called septum posticum. This septum connects the periosteum of the vertebral bodies to the posterior longitudinal ligament, preventing a fragment to move from one side to the other ${ }^{(\mathbf{6})}$. A fibrous lateral (peridural) membrane defined by Fick, with one fourth of the resistance of the dura, also acts as hurdle. This membrane is located anteriorly to the posterior longitudinal ligament, attached to its deep margin. The ligament of Hoffmann, which connects the posterior longitudinal ligament to the dura, also acts as a firm boundary. The posterior longitudinal ligament, the ligaments listed above, dura, and the other wellknown structures of the epidural space (nerve roots, epidural venous plexus of Batson and the epidural fat), certainly restrict the migration of a disc fragment mainly to the anterior and anterolateral epidural space ${ }^{(2,4,7)}$

Patients with posterior migration of a herniated disc may complain of low back pain or radiculopathy, but commonly will present with cauda equina syndrome ${ }^{(\mathbf{1})}$. Traction therapy a common chiropractic treatment should be avoided in cases of posterior migration because the symptoms may be aggravated and further worsening the cauda equina syndrome $e^{(2,5,8)}$.

MRI is the diagnostic modality of choice $^{(9)}$. The migrated disc usually appears similar, although not identical to the cerebral spinal fluid signal intensity and exhibits rim enhancement on the post contrast sequences ${ }^{(\mathbf{6})}$. Computed tomography usually demonstrates a soft tissue nodule indenting and displacing the dural sac anteriorly.

There are several differential diagnoses with overlapping features for a posterior epidural mass ${ }^{(2)}$, which mainly include meningioma, metastasis, lymphoma, hemangioma, synovial cyst ${ }^{(\mathbf{1 0 , 1 1})}$, abscess and epidural hematoma. Meningiomas and hemangiomas usually reveal a solid and rather homogeneous post contrast enhancement. In cases of metastases and lymphomas the patients usually present with multisystem involvement and marrow abnormalities. Abscesses and hematomas usually demonstrate peripheral rim of enhancement with an associated infectious illness or history of trauma.

The importance of contrast study has been described in the imaging literature for 


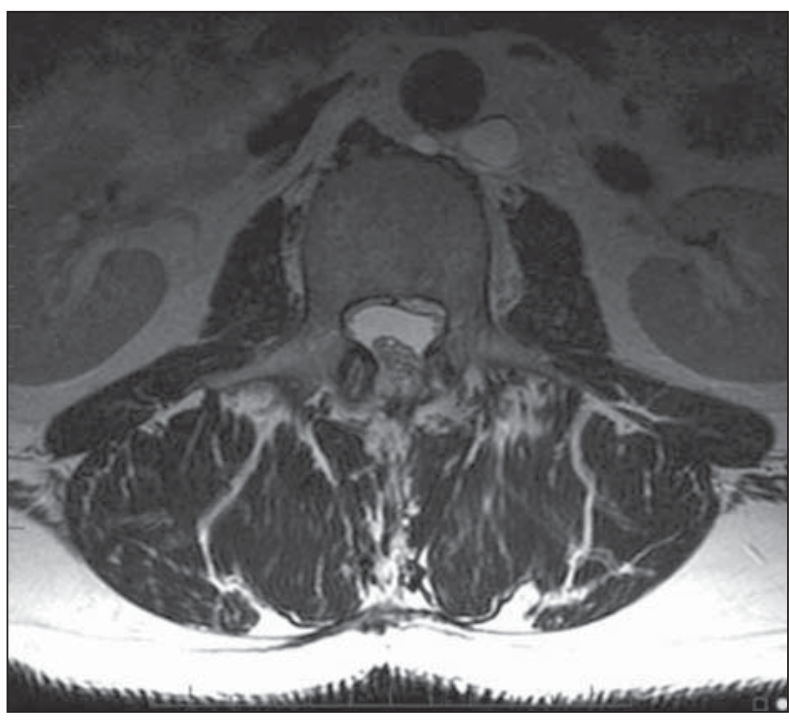

Figure 3. Axial T2WI 60 days after surgery demonstrates significant improvement of the compression of the cauda equina roots and the abscence of any residual disc in the epidural space.

accurate diagnosis ${ }^{(6)}$. In our case contraindication for contrast study was an imaging dilemma and we had to rely significantly on the clinical history. The diagnosis was confirmed intra-operatively and on followup scan with significant symptom relief.

\section{CONCLUSION}

$\mathrm{DH}$ with posterior epidural migration is a rare entity most frequently occurring at L3-4 level with variable symptomatic presentation. The majority of the patients with DH with PEM present cauda equina syndrome rather than radiculopathy. Contraindication for contrast administration makes delay diagnosis and treatment.

\section{Key points}

1. PEM of a disc fragment is very rare.

2. Posterior longitunal ligament, midline septum posticum, peridural membrane, ligament of Hoffman, dural sac, epidural fat, venous epidural plexus of Batson and neural roots form a natural barrier from disc PEM.

3. Enhanced MRI is the diagnostic modality of choice.

\section{REFERENCES}

1. Teufack SG, Singh H, Harrop J, et al. Dorsal epidural intervertebral disk herniation with atypical it an imaging dilemma, which may further radiographic findings: case report and literature review. J Spinal Cord Med. 2010;33:268-71.

2. Dösoğlu M, Is M, Gezen F, et al. Posterior epidural migration of a lumbar disc fragment causing cauda equina syndrome: case report and review of the relevant literature. Eur Spine J. 2001;10: $348-51$.

3. Fardon DF, Milette PC. Nomenclature and classification of lumbar disc pathology. Recommendations of the Combined task Forces of the North American Spine Society, American Society of Spine Radiology, and American Society of Neuroradiology. Spine. 2001;26:E93-E113.

4. Sengoz A, Kotil K, Tasdemiroglu E. Posterior epidural migration of herniated lumbar disc fragment. J Neurosurg Spine. 2011;14:313-7.

5. Lichtor T. Posterior epidural migration of extruded lumbar disk. Surg Neurol. 1989;32:311-

6. Kim JS, Lee SH, Arbatti NJ. Dorsal extradural lumbar disc herniation causing cauda equina syndrome : a case report and review of literature. J Korean Neurosurg Soc. 2010;47:217-20.

7. Wiltse LL, Fonseca AS, Amster J, et al. Relationship of the dura, Hofmann's ligaments, Batson's plexus, and a fibrovascular membrane lying on the posterior surface of the vertebral bodies and attaching to the deep layer of the posterior longitudinal ligament. An anatomical, radiologic, and clinical study. Spine. 1993;18:1030-43

8. Kraemer J. Intervertebral disk diseases: causes, diagnosis, treatment, and prophylaxis. 3rd ed. Stuttgart, Germany: Thieme; 2009

9. Chen CY, Chuang YL, Yao MS, et al. Posterior epidural migration of a sequestrated lumbar disk fragment: MR imaging findings. AJNR Am J Neuroradiol. 2006;27:1592-4.

10. El Khamary SM, Alorainy IA. Case 100: spinal epidural meningioma. Radiology. 2006;241:614-

11. Lee JW, Cho EY, Hong SH, et al. Spinal epidural hemangiomas: various types of MR imaging features with histopathologic correlation. AJNR Am J Neuroradiol. 2007;28:1242-8. 